\title{
Innovative Leadership Style for Industrial Companies
}

\author{
Mag. Christine Aschbacher, Jozef Sablik \\ Department of Industrial Engineering, Slovak University of Technology, Bratislava, Slovakia
}

Email address:

xkowald@is.stuba.sk (M. C. Aschbacher), jozef.sablik@stuba.sk(J. Sablik)

\section{To cite this article:}

Mag. Christine Aschbacher, Jozef Sablik. Innovative Leadership Style for Industrial Companies. Science Journal of Business and Management. Vol. 7, No. 2, 2019, pp. 45-50. doi: 10.11648/j.sjbm.20190702.11

Received: May 2, 2019; Accepted: June 15, 2019; Published: June 26, 2019

\begin{abstract}
Innovation is a hot topic for industrial companies especially in a competitive environment. As there is a lack of innovation in combination with leadership style, the aim of the paper is to combine these factors as inputs for leaders of tomorrow for industrial companies. Nowadays leaders are looking for a new kind of leadership style, which drives the innovation in the company too. The theoretic perspective is being considered with the basic leadership styles as well as with input of some international successful leaders of innovative companies. The trends of a practical orientation of a specific industrial sector provide with their findings and tips for successful innovative leadership. The leaders of tomorrow will find some solution approaches for their leadership styles in innovative companies so that they can enhance the innovation power in their industrial companies.
\end{abstract}

Keywords: Innovation, Leadership Style, Industrial Sector, Spirit

\section{Introduction}

The topic of leadership is getting more and more important and after decades of different leadership stiles, the question raised if there is a connection between leadership stile and innovation. In this paper the definition of leadership will be explained at the beginning. In the main part the aspect of innovation and its criteria are being defined as well as an excerpt from a qualitative survey with manager of an industrial sector according to innovative leadership. Finally, the summary will close with the most important findings.

\subsection{Leadership Styles}

A leadership style is to support leadership as a management function. In summary, some styles, which are considered to be frequently used, are described as examples.

\subsubsection{The Theorie $Z$}

It is based on a comparison by Ouchi (1981) of the leadership in American and Japanese companies with the result that the successful American and Japanese companies are the most successful. Companies come very close in their management style to Japanese companies. Type $\mathrm{Z}$ companies are characterized by an established and homogeneous corporate culture. Building on this, Ouchi proposes a 13- stage (organizational) development model for a Type $\mathrm{Z}$ organization for the less successful American companies. Company. In doing so, it aims to redirect attention to human relationships in the entire organizational community. [1]

\subsubsection{The 7F-Model}

The leadership style developed by McKinsey (Pascale and Athos, 1981) points to the need to optimally use and coordinate the following 7Fs in order to achieve corporate goals: leadership strategy, leadership skills, leadership system, leadership style, leadership structure, leadership goals/concepts as well as the target and value system of the executives. There is no generally binding solution; rather, each company must develop its own 7F profile, which is "optimal" only for it. [2]

\subsubsection{Strategic Position of Success}

The leadership style developed by Pümpin (1982) emphasizes the need to coordinate strategy, culture and leadership systems (misfit analysis). A successful position is a prerequisite consciously created in an enterprise through the acquisition of skills, which should enable it to achieve above-average results in comparison to its competitors. It must not be readily copyable by the competition and must be based on prerequisites that are highly promising for the future (strategic basic attitude). In order to secure their long- 
term success, all leadership-relevant systems must be geared to the expansion of the strategic success position: Power centres, employee development, reporting, strategies, planning, disposition, organization, leadership style, management deployment and working methods. [3]

\subsection{Leadership Approaches}

Different leadership approaches are being used by leaders. Historical used leadership approaches as well as the approaches from the system point of view.

\subsubsection{Development of State-of-the-art Leadership}

Empirical leadership research goes back to a series of field experiments conducted by psychologists Kurt Lewin from 1938 to 1940 at the University of Iowa, in which he investigated the extent to which different leadership behaviour affected the creativity, productivity, working climate, etc. of groups. [4] Starting from this, different basic patterns were developed in the course of the last century in the history to describe the leadership theories. Four basic directions are particularly concise:

(1) the property approach,

(2) the behavioural approach,

(3) the situation approach and

(4) the system approach.

The property approach assumed that the character traits were responsible for the success of a manager. The behavioural approach developed this aspect further, based on the assumption that not only the characteristics of a person enable successful leadership and therefore primarily dealt with the question of which leadership style can achieve the best results. The situation approach has again adopted many thought patterns of the behavioural approach, but additionally includes the immediate framework conditions by asking the question in which situation one achieves the best success with which leadership style. The focus is on the description of the respective leadership situation. The basis for the current further development of leadership theories is the system approach. The paradigm that has prevailed to date with its simple laws and dependencies, according to which people and social systems can be fully controlled, has lost importance in this context. The highly complex interaction processes between human action and system behavior are included in this approach. [5]

\subsubsection{The Understanding of Leadership in the System Approach}

The system approach results in an understanding of leadership that understands itself as a subset, albeit only temporarily predominant, of the processes taking place individually in a social system. Successful leadership, understood in this way, presupposes a correct interpretation of these social processes and today no longer consists only of the objective of achieving the desired behaviour of employees, but rather comprises all requirements for the design of optimal framework conditions under which the members of a system can organise their tasks autonomously.
According to Hans Martin Ulrich, it is not the behaviour of individuals but the behaviour of social systems that is the subject and problem of management. The model of 'Integrated Management' developed by Ulrich and its employees in the $60 \mathrm{~s}$, continued by Knut Bleicher and still today described as the HSG- approach, includes following attributes: [6]

(1) System thinking: Decisions should be taken taking into account the overall and interdependency relationships.

(2) The orientation of management should change from technocratic to human, cultural and systemic orientation.

(3) The steering function of management should be abandoned in favour of a design and development function.

Systemic management thus handles social 'wholeness' on the basis that they have their own tradition and individual overall structure and culture. [7]

\subsubsection{Leaders use Sponsorship-claims Matrix for Driving Innovative Leadership}

Communication always has an effect. The behavior of helping others is called fostering. The behavior of listening to one's own needs is called demanding. This tool will provide the most effective improvements for both executives and employees to push innovation. [8]

\section{Main Findings of Innovative Leadership}

\subsection{Industrial Companies of Innovation}

When an industrial enterprise is described as innovative and when it is non-innovative is a challenging distinction in the literature. The definition for the innovation criteria was chosen.

\subsection{Evaluation of Innovation Criteria}

The evaluation of the innovation projects is carried out according to points in the individual criteria and compared with a minimum number of points in each case. The evaluation in the individual criteria is based on the following topics and examples of positive (+) and negative (-) aspects for the evaluation. [9]

Corporate strategies and innovation potentials

The evaluation will focus on which core competencies and traditional business areas exist in the company and how these relate to the corporate goals and strategies or innovation potentials identified by the innovation project.

+ Comprehensible strategy, objectives achievable in terms of quality and scope

+ Central importance of the innovation project for the corporate strategy

- Existing business segments that are barely consolidated in terms of market success

- Low positive impact on employment and value added at the site 
Organizational structure and project management

The existing organizational structures in the company or corporate environment and their compatibility with the requirements arising from the handling of the innovation project are evaluated.

+ Sustainable integration of relevant organizational areas into the innovation project

+ Access to necessary resources and competencies internally and externally

- Lack of clarity or low level of detail in project planning

- Functional overload of the innovation assistant

Market expectation and project exploitation

The assessment includes the needs of the end customer, the assessment of the current market situation (e.g. competition, other technologies) and the measures taken to reach the customer (marketing, sales, product service mix, etc.).

+ Evidence of market expectation or market access

+ Early considerations for (improved) operative implementation on the market

- Rough derivation of general market conditions for situations in niche markets

- Missing survey of the customer's point of view

Type of innovation and level of innovation

The novelty content of the project results in relation to existing products, processes or structures and the innovative step achieved with the project are evaluated.

+ Significant expansion of core competencies, integration of external knowledge

+ Substantial investment in operation-specific innovations with a clear reference to the latest technologies

- Low direct relevance to market success

- Excessive risk compared to competence base

Project and innovation management

The project evaluates the extent to which innovationrelevant factors such as the ability to cooperate, internal innovation management, research \& development or the use of funding instruments are strengthened in comparison to previous practices.

+ Need for external consulting to increase the propensity to innovate

+ Employment of university or university of applied sciences specialists not yet a matter of course (low proportion of academics)

- Low backlog demand, comprehensive experience in dealing with innovations

- Short-term innovative effort in terms of time and content

\subsection{Innovative Leadership}

As a beginning innovative leadership style, which already exists in literature, the style of successful entrepreneurs like Richard Branson or Steve Jobs can be used. Whereby this hardly contains a model, but more experiences from their innovative enterprises, which concerns the high-level personnel, describe and as tips pass on. However, these are not produced in relation to industrial companies, which suggests that they have not yet been literarily edited.

Innovation leadership commonly includes four basic stages, which are: support for idea generation, identifying innovations, evaluating innovations, and implementation. There are two types of innovations, including: exploratory innovation, which involves generating brand new ideas, and value-added innovation, which involves modifying and renewing ideas that already exist. The key role in the practice of innovation leadership is that of the innovation leader. However, there are currently multiple perspectives on the definition of an innovation leader. An individual in an organization, a group within an organization, the organization itself, and even a community, state, or nation can be considered an innovation leader. [10]

\subsubsection{The Role of Leadership}

The leadership team should undertake initial activities to set the context for any change of innovation. Leadership needs to define the innovation strategy and link it to the business strategy. Following questions need to be answered by the leadership team:

(1) Vision: What do you want?

(2) Values: Whats important about it?

(3) Methods: How to you get it?

(4) Obstacles: What is preventing you from getting it?

(5) Measures: How will you know when you got it?

These questions need to be answered as the leader will focus on innovative actions. [11] Not everyone is eligible to be CEO

A manager needs someone who 'brings the best to people', someone who communicates well with others and helps an employee learn from a mistake instead of criticizing them for it.

Not everyone does this too, and that's okay. The founder may but does not have to be the CEO; if the fit is not right, he or she should know when the role is meant for someone else.

Branson sees the classic image of the 'boss' as an anachronism. Heroic is not a desirable characteristic in a manager, he says. A boss does orders, while a leader organizes.

'Perhaps, therefore, it is strange that if there is any one phrase that is guaranteed to get me on the way, it is when someone says to me: Okay, fine. You're the boss!' says Branson. 'What annoys me is that in 90 percent of the cases, like what this person really wants to say is: 'Okay, then, I don't think I agree with you, but I'll roll over and do it because you tell me to. But if it doesn't work out I will be the first to remind you that it's not my idea.'

A good innovative business leader is someone who not only has to execute his own ideas, but also inspires others to come forward with their own ideas. [12]

Innovation concerns creating new values together with others. Authenticity, can be seen as inner and backwards, while innovation is outer and forwards. Both can be found in innovation competency as a foundation of knowledge about innovation so that the personality of the leader is the key success factor for innovation drive in a company. [13]

\subsubsection{Innovative Leadership at the Company Apple}

Steve Jobs leaves Apple in great shape. His position as 
CEO leaves the chairman position but leaves an innovation leadership legacy that is transformative to maintain. There is no leader in this day and age who was more innovative, who broke more rules and invented more things that have changed our world.

It describes an employee who was part of the team that started the Macintosh computer. He was active in business strategy, strategic planning and managed global business markets, industries such as medicine were his passion and focus.

These were described as exciting times, aware that they sparked a revolution like people in computers, information and culture. [14]

Each leader needs to think in a positive way

You have the first big vision to sell the employees. If they do not get, then customer never. This seems obvious, but too many leaders today have the right finances or seniority or even board support but do not embody this lesson. Steve invented it.

Days before the Mac they start sent to take pictures of a Swiss army knife, challenging that Mac was something else, not just a computer, but a lifestyle device. Steve asked them to think about the Mac as more than just a technology - it was an innovation in culture, lifestyle and learning.

Think differently to differentiate your company or product

Steve was all about innovative marketing, product features, design, packaging, he knew that specifically thinking differently was the key to Apple's differentiation from the mass of companies.

When they launched the Mac to the media and they wanted a Mac in every room, without a manual. Other computers, like IBM came up with huge manuals on how to work. When the analysts came into their rooms they expected to touch the computer. The Mac would turn on and hear them from the computer "hello". This blew their mind. Steve was always sure that our minds blew with innovative ideas.

Take smart risks, fast downtime and don't give up

People forget that Apple tried and failed at many things before success. They learn more from mistakes then successes. Edison's light bulb took 40,000 mistakes to make it right. Before the Mac computer, the Lisa failed. Apple had a run on one in an early iPad called Newton, he did not make it. Taking risks and persevering is important.

Enjoy the journey

Everyone's here on the planet for a limited window. Make the most of it.

Steve would remind us all to enjoy the trip. Or don't they. He urged them all to make a commitment to do something themselves too big, important and meaningful. These lessons are as true today as they were in 1984.

Invest in the future

This is the big chance. As sustainable, this is what life and it goes in business. When they go to invent the future, they must be willing to take risks, make mistakes, but most importantly: Think in big ideas. Sell your big idea, your innovation is what every leader needs to do every day. Steve was and is a fearless leader who invented the future: Mac,
iPod, iPad, iTunes, Apple TV, the mouse ... and a software interface, all adopted for 20 years.

\subsubsection{Innovative Leadership in the 21st Century}

A new phenomenon to philanthropy was born through the Clinton Foundation that enabled Bill Clinton exemplified leadership through transformational leadership, understanding of his memes and the followers' memes that enabled him to create a forum where actors from various sectors use as a vehicle to make commitments that are measurable. The success of the Clinton Foundation stemmed from Clinton's ability to show a Level Three Leadership skill that encompasses congruency, empathy, faith, trust, and non-judgmental demeanour towards subordinates and colleagues. [15]

In the world of work, the single greatest asset of successful individuals, teams, and organizations is their mindset-what happens in between their ears. It is not the corporate strategy, the sales compensation plan, or the market segments they are pursuing. It is what each leader, team member, and employee choose to focus on, believe, and create innovations for themselves and others: it is not what others tell you, it is what you tell yourself. [16]

\subsubsection{Imperative of Innovative Leaders}

Creation of an innovative climate is the highest priority for innovative leaders. Employees need extrapreneurs for leading them. A key task for innovative leaders is to recruit an effective team with different functional backgrounds, personalities and thinking styles to play different roles. One further main task is to manage innovative teams to focus on new ideas and creativity. Developing skills means to develop openness and awareness so that people understand themselves and others better. [17]

For the regular routine to keep the innovation in the organisation, leaders should ask what business they are in as well as ask people who consider to buy their products or not. One definition of innovation in business is an action that extends customer value. For innovation there is a need to understand what it is that the customer really values. Then it can set in their minds to the task of how to extend that value. The proposal is to start every week by asking two questions: what do customers really values and what business they are in. [18]

\section{Practical Orientation of Industrial Companies for Innovative Leadership}

For the empirical survey, industrial enterprises that are business partners in a sector of the coatings industry were examined. This industry was chosen as the survey group because the market is so dynamic that there is no existence on the market without innovations.

Selected executives working in the innovation sector in this segment were interviewed.

\subsection{Cross-sectional Analysis}

Within the cross-sectional analysis, it is centrally evident 
that all the industrial companies surveyed recognise a lack of a model of innovative leadership style. All companies want to drive the innovation process but are hardly able to carry it out with the existing managers, because these requirements are not set. There is always the mood to implement a leadership style in the innovation area by chance that is neither measurable nor comprehensible. This results in the result that the key positions of the innovative leader are based on personal relationships with business partners and can therefore be transferred or continued to a limited extent.

For this reason, there are recommendations for action that these companies can implement at management level in the area of innovation. This empirical survey did not find any connection between corporate success and innovative leadership style. None of the managers who deal with and drive innovations on a daily basis mentioned statements about their leadership style or interrelationships.

In the following, based on the empirical surveys, three points are considered important in summary, which the managers can see as recommendations for action in the innovative field.

\subsubsection{Positioning of the Innovative Company on the Market}

Due to the high competition in the industry, it is recommended to focus on the values of the respective company and to position them externally - towards the customer (What do we stand for?).

Furthermore, niche products can be included in the product range or anchored and transported (What makes us special?).

To become visible to the customer means to implement the innovation and make it visible. Managers in the innovation sector are responsible for this and at the same time overburdened with this expectation.

\subsubsection{Communication und Infrastructure}

Continuous availability of the contact person of the innovative manager as "single point of contact" or competent representation (information to the customer in advance) is recommended as a success factor for innovative industrial companies. As well as making the order status accessible for customers and thus letting the customer participate in the innovation process of the company, as well as mediating via concrete and tailor-made communication instruments from the innovative executive.

\subsubsection{Relationship Management}

The personal business partner relationship is still important for the respondents. Without this factor, an innovative leader will not be able to drive the innovation process forward.

Therefore, intensive relationship support, highlighting of the company's experience, especially with regard to the innovative area, up to the customer as well as queries, what works well, improvement suggestions and wishes to the customer.

\subsection{Summary of Practical Orientation}

In summary, it can be emphasized that in practice there is a lack of orientation of leadership styles in innovative industrial companies. These executives are expected to have high expectations, which are unclearly defined and therefore the leadership style is unclear. Regardless of internationality or orientation, the personal business partnership is the critical success factor to drive the innovation process. Numerous quantitative key figures and reports function in the innovation process.

\section{Conclusion}

If theoretical findings are considered together with practical results, then there are some approaches in the literature that suggest innovative leadership styles. The innovation process is often described and innovation has become more and more an essential topic in the industrial landscape. Not only for companies, but for the entire business process chain. Leadership styles have been highlighted in different ways for several decades, but not with a focus on innovation. What makes an innovative manager special and how does this positively affect the company is hardly to be found in literature. The renowned Richard Branson describes it in his book "Like a Virgin: Secrets, they don't teach you at business school". In his approach, this means that someone who runs a highly innovative company should not be a boss of the old school, but a leader who brings the best into the company and drives innovation processes. The key to the success of the innovation company is a manager who does not delegate his own topics, but also develops the ideas of others - by they employees or business partners - in the field of innovation and ensures their implementation and success. Together with the outcome of the practical orientation the personality of the manager is the most important factor of the innovation degree in the leadership perspective. The innovative leader of the successful company, Steve Jobs, was also highlighted as a summary that the spirit of leadership is decisive for the degree of innovation in the company.

\section{References}

[1] Ouchi, W. (1981): How American Business Can Meet The Japanese Challenge: How American Business Benefits from Japanese Management Models. Japan.

[2] McKinsey (2015): 7s framework: Boost business performance, prepare for change and implement effective strategies. San Francisco.

[3] Pümpin, C., Amann, W. (2005): SEP. Strategic Success Positions: Build and Implement Core Competencies. Haupt, Bern.

[4] Lewin, K. (1947): Field theory in social science. New York.

[5] Lück, H. E. (2003): Managing change and transition. Harvard Business School Press. Boston.

[6] Bleicher, K. (1996): The concept of integrated management. Frankfurt/ Main-New York. 
[7] Ruegg-Stürm, J. (2003): The new St. Gallen Management Model: Basic categories of integrated management theory. The HSG approach. Bern/ Stuttgart/ Wien.

[8] Winterheller, M. (2003): When mountains rise up. Graz.

[9] Hauschildt, J., Salomo, S. (2011): Innovation Management, München.

[10] Gliddon, D., Rothwell, W. (2018): Innovation Leadership. New York.

[11] Moore, T., Neidlinger, A. (2014): How to became innovative. New Jersey.

[12] Branson, R. (2012): Like a Virgin: Secrets They Won’t Teach You at Business School. Great Britain.
[13] Darso, L. (2013): Developing authentic, innovative leaders. In Ladkin, D., Spiller, Ch. (Ed): Authentic Leadership. Cheltenham, Northampton.

[14] Isaacson, W. (2011): Steve Jobs. New York.

[15] Kotter, J. P. (1996) Leading Change. Harvard Business School Press. Boston.

[16] Blane, H. (2017): 7 Principles of Transformational Leadership: Create a Mindset of Passion, Innovation, and Growth. New York.

[17] Hender, J. (2003) Innovative Leadership. London.

[18] Sloane, P. (2007): The Innovation Leader. London and Philadelphia. 